\section{A) Check for updates}

Cite this: Polym. Chem., 2021, 12, 2122

Received 13th January 2021, Accepted 11th March 2021

DOI: $10.1039 / \mathrm{d} 1$ py00048a rsc.li/polymers

\title{
RAFT miniemulsion polymerisation of benzyl methacrylate using non-ionic surfactant $\uparrow$
}

\begin{abstract}
Shang-Pin Wen, (DD ${ }^{a}$ Qi Yue (D) ${ }^{a}$ and Lee A. Fielding (D)*a,b
Miniemulsion polymerisation has become widely recognised as a versatile and efficient strategy to prepare well-defined polymer latexes. In this article, we report the synthesis of poly(benzyl methacrylate) (PBzMA) latexes via reversible addition-fragmentation chain-transfer (RAFT) mediated miniemulsion polymerisation using non-ionic Lutensol TO 20 surfactant. The influence of hydrophobe, initiator, and RAFT agent on particle diameter, particle number, rate of polymerisation, and molar mass were investigated systematically. In all cases well-controlled RAFT polymerisations were observed, as indciated by kinetic studies and GPC analysis. Higher concentrations of hexadecane lead to an increase in the of number of particles per unit volume and a decrease in PBzMA latex diameter. The rate of polymerisation with respect to initiator concentration follows a power-law relationship $R_{\mathrm{p}} \alpha$ [initiator] $^{1 / 2}$ but only negligible differences in molar mass, molar mass dispersity, and particle diameter values were observed for a range of initiator concentrations. Targeting lower PBzMA degrees of polymerisation increases the overall rate of polymerisation and latex diameter.
\end{abstract}

\section{Introduction}

Reversible-deactivation radical polymerisation (RDRP) is a versatile technique for the synthesis of well-defined polymers and has attracted both academic and industrial attention in the past decade. ${ }^{1-3}$ The three main RDRP techniques are nitroxide-mediated polymerisation (NMP) ${ }^{4-6}$ atom-transfer radical polymerisation (ATRP), ${ }^{7,8}$ and reversible addition-fragmentation chain-transfer (RAFT) polymerisation. ${ }^{9-12}$ These techniques afford the capability to control radical polymerisations to obtain polymers with narrow molecular weight distributions and complex architectures. RDRPs are typically performed in homogeneous media which often require the use of undesirable volatile organic compounds (VOCs) for the control of heat evolution and viscosity of a given polymerisation. However, RDRP performed in heterogeneous conditions, such as emulsion, miniemulsion or dispersion polymerisation, has gained increasing attention in recent years. ${ }^{13-16}$ Common advantages

\footnotetext{
${ }^{a}$ Department of Materials, School of Natural Sciences, University of Manchester, Oxford Road, Manchester, M13 9PL, UK. E-mail: lee.fielding@manchester.ac.uk ${ }^{b}$ Henry Royce Institute, The University of Manchester, Oxford Road, Manchester, M13 9PL, UK

$\dagger$ Electronic supplementary information (ESI) available: Experimental details of the synthesis of PETTCCP and PETTC RAFT agents; experimental characterisation details; studies on the synthesis of PBzMA using conventional miniemulsion polymerisation; CMC determination for SDS and Lutensol TO 20; kinetic studies for miniemulsion polymerisation of PBzMA using various RAFT agents; GPC chromatograms from self-blocking experiments. See DOI: 10.1039/ d1py00048a
}

of heterogeneous polymerisation include the use of water as a continuous phase (as a more environmentally friendly solvent) and low viscosity of the polymerisation medium due to the formation of discrete polymeric particles. ${ }^{17}$ In particular, RAFT polymerisation has attracted wide attention in the past few decades because it can be applied to an extensive range of functional monomers and be performed under moderate conditions. ${ }^{10}$ In addition, it has been demonstrated that RAFT polymerisation can be conducted via various heterogeneous routes such as RAFT emulsion polymerisation ${ }^{18,19}$ and RAFT miniemulsion polymerisation. ${ }^{20-24}$

Miniemulsion polymerisation is a heterogeneous polymerisation technique widely used to prepare well-defined vinyl polymer latexes. ${ }^{25-28}$ Miniemulsions are normally defined as aqueous dispersions of relatively stable oil droplets (50-500 $\mathrm{nm})$ prepared by applying shear to a system containing water, oil, surfactant and hydrophobe. ${ }^{29}$ Miniemulsion droplets are considered metastable but their stability during a miniemulsion polymerisation is crucial because it affects the polymerisation kinetics and resulting latex morphology. ${ }^{30,31}$ Typical miniemulsion formulations are based on anionic surfactants (e.g. sodium dodecyl sulfate, $\operatorname{SDS}^{32}$ ) in combination with a selectively oil-soluble hydrophobe (e.g. hexadecane, ${ }^{31}$ dodecyl mercaptan, ${ }^{33}$ or reactive alkyl methacrylate ${ }^{34}$ ). Nevertheless, the influence of cationic and non-ionic surfactants on miniemulsion polymerisation has been reported. For example, Landfester et al., ${ }^{35}$ demonstrated polystyrene latexes synthesised using cetyl trimethylammonium bromide (CTAB) cationic surfactant had similar particle sizes when compared 
to those prepared using SDS. Hecht et al., ${ }^{36}$ investigated miniemulsion polymerisation of styrene using a non-ionic surfactant. It was shown that the non-ionic surfactant had slower adsorption and desorption kinetics than SDS, minimising its presence in the continuous phase. This led to newly formed oligomeric species being incorporated within existing droplets before precipitating and thus nucleation of new particles was not observed.

In RAFT miniemulsion polymerisation, a small amount of hydrophobic chain-transfer agent (CTA) is dissolved in the monomer phase prior to emulsification. ${ }^{37,38}$ Polymerisation control and latex stability in RAFT miniemulsion polymerisation using conventional RAFT agents has been reported utilising relatively high concentrations of surfactant and hydrophobe. ${ }^{18,39,40}$ However, the use of RAFT agents in miniemulsion polymerisation is sometimes problematic, causing colloidal instability, ${ }^{41,42}$ broad particle size distributions, ${ }^{20,43}$ low polymerisation rates, ${ }^{44,45}$ low monomer conversions ${ }^{32,46,47}$ and broad molecular weight distributions. ${ }^{4-51}$ Furthermore, some RAFT miniemulsion polymerisation systems experience inhibition or retardation of the polymerisation. ${ }^{20,44}$

Acrylic and methacrylic monomers are crucial for manufacturing of a wide range of polymeric materials for a variety of applications. $^{52,53}$ Among this group of monomers, benzyl methacrylate (BzMA) is a hydrophobic methacrylic monomer which is often used as a substitute for styrene. For example, in RAFT-mediated PISA, ${ }^{54-56}$ BzMA acts as water-immiscible monomer which exhibits higher polymerisation rates than styrene, ${ }^{9}$ minimising unreacted monomer in these formulations. ${ }^{57}$ Furthermore, a wide range of potential applications of PBzMA have been explored, such as: polymeric optical fibres $;^{58}$ nanoimprinting lithography; ${ }^{59,60}$ inkjet inks; ${ }^{61}$ contact lenses; ${ }^{62}$ coatings and paints; ${ }^{63,64}$ adhesives ${ }^{65,66}$ microtubes; ${ }^{67}$ monoliths for capillary electrochromatography ${ }^{68}$ colour filter photoresist materials; ${ }^{69}$ stationary phases in liquid chromatography; ${ }^{70,71}$ and in ionic liquids. ${ }^{72-74}$ However, to the best of our knowledge, there are relatively few reports which investigate the effects of the RAFT process on the kinetics of miniemulsion polymerisation of BzMA.

Herein we report the preparation of PBzMA via RAFT miniemulsion polymerisation. More specifically, a series of PBzMA latexes have been prepared by systematically adjusting the concentration of hydrophobe, initiator, and RAFT agent

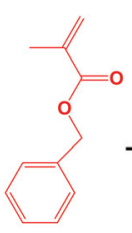

BzMA

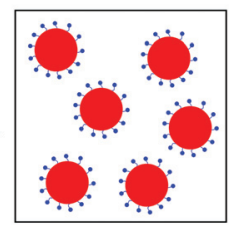

PBzMA latex
Scheme 1 Synthesis of poly(benzyl methacrylate) (PBzMA) latex via RAFT miniemulsion polymerisation at $70{ }^{\circ} \mathrm{C}$ using Lutensol TO 20 nonionic surfactant. Polymerisations were conducted at a dispersed phase content of $20 \% \mathrm{w} / \mathrm{w}$.
(Scheme 1). This has allowed us to extend the knowledge of the rules which govern latex formation during RAFT miniemulsion polymerisation. In this work, we screened chain transfer agents with different hydrophilicity, and surfactants including a conventional anionic surfactant (SDS) and a series of Lutensol TO non-ionic surfactants to ascertain a suitable surfactant for miniemulsion polymerisation of BzMA. The resulting PBzMA latexes were characterised via gravimetry, DLS, GPC, and TEM. Furthermore, we demonstrate that miniemulsion polymerisations with tuneable polymerisation rate, PBzMA molar mass, number of particles per unit volume, and particle diameter can be conducted by altering the concentration of hydrophobe, initiator, or RAFT agent.

\section{Experimental}

\section{Materials}

Sodium dodecyl sulfate (SDS, 98.5\%), hexadecane (HD, 99\%), and azobisisobutyronitrile (AIBN, 98\%) were purchased from Sigma-Aldrich (UK) and used as received. The non-ionic Lutensol surfactants, e.g. Lutensol TO 20, which is a saturated iso- $\mathrm{C}_{13}$ alcohol with an ethoxylation block length of 20 units (iso- $\mathrm{C}_{13} \mathrm{H}_{27} \mathrm{O}\left(\mathrm{CH}_{2} \mathrm{CH}_{2} \mathrm{O}\right)_{20} \mathrm{H}$, molar mass $\left.=1000 \mathrm{~g} \mathrm{~mol}^{-1}\right)$, were obtained from BASF (UK) and used as received. Benzyl methacrylate (BzMA, 98\%) was purchased from Alfa Aesar (UK) and passed through a column of activated basic alumina to remove inhibitors and impurities before use. Tetrahydrofuran (THF, HPLC grade) was purchased from VWR International (UK) and used as received. Chloroform-d $\left(\mathrm{CDCl}_{3}\right)$ was purchased from Cambridge Isotope Laboratories (UK). 4-Cyano-4-(2-phenylethanesulfanylthiocarbonyl)sulfanyl pentanoic acid (PETTC) and bis-(2-phenylethanesulfanyl thiocarbonyl) disulphide (PETTCCP) were prepared in-house using previously published methods (ESI $\dagger$ ). ${ }^{75,76}$ Deionised water was used in all experiments.

\section{Synthesis of poly(benzyl methacrylate) via RAFT miniemulsion polymerisation}

In a typical protocol, the synthesis of $\mathrm{PBzMA}_{300}$ via RAFT miniemulsion polymerisation was conducted at a dispersed phase content of 20\% w/w, using: BzMA (7.8 g, $44.087 \mathrm{mmol}$ ); PETTCCP (41.4 mg, $0.147 \mathrm{mmol}$ ); AIBN (4.8 mg, $0.029 \mathrm{mmol}$, $[\mathrm{CTA}] /[$ initiator $]=5)$; TO $20(604.0 \mathrm{mg}, 7.8 \% \mathrm{w} / \mathrm{w}$ related to BzMA); HD (185.2 mg, 2.4\% w/w related to BzMA); and water (31.4 g). The dispersed and the aqueous phases were prepared separately. The dispersed phase was prepared by thoroughly mixing BzMA, HD, AIBN and CTA (PETTC or PETTCCP, if used) by magnetic stirring until homogeneous. The dispersed phase was then added to the aqueous solution of Lutensol TO 20 non-ionic surfactant under vigorous stirring at $800 \mathrm{rpm}$ for $60 \mathrm{~min}$ to form a coarse emulsion. This coarse emulsion was ultrasonicated using an ultrasonic processor CPX-750 (Cole Palmer, maximum output power of $750 \mathrm{~W}$ ) at an amplitude of $70 \%$ for $5 \mathrm{~min}$ (10 seconds pulse on and 5 seconds pulse off) in an ice-water bath to prevent overheating during miniemulsification. The obtained miniemulsion was then transferred to a 
$100 \mathrm{~mL}$ two-necked round-bottom flask equipped with a condenser and a nitrogen inlet. The reactor contents were deoxygenated by purging with nitrogen for $10 \mathrm{~min}$ at room temperature. After deoxygenation, the round-bottom flask was immersed into a preheated oil bath at $70{ }^{\circ} \mathrm{C}$, corresponding to time zero of the polymerisation. The reaction was heated for $240 \mathrm{~min}$ and magnetically stirred at $150 \mathrm{rpm}$. Samples were periodically withdrawn with a degassed needle from the bottom of the flask to monitor the conversion of monomer and the evolution of molar mass. Polymerisations were quenched by cooling to room temperature and exposing to air. Experimental conditions for all the miniemulsion polymerisations performed in this study are given in Tables 1-3.

\section{Characterisation}

Monomer conversions during polymerisations were determined by gravimetry. Samples were withdrawn from the reactor at different times and weighed (approximately $1.0 \mathrm{~g}$ ) in $7 \mathrm{~mL}$ vials. After weighing, the samples were immediately quenched with approximately $10 \mu \mathrm{L}$ of $1 \% \mathrm{w} / \mathrm{w}$ hydroquinone in an ice-water bath. The specimens were placed in an oven and dried at $60{ }^{\circ} \mathrm{C}$ to constant weight. Conversions were calculated from the measured dry residue.

Dynamic light scattering (DLS) studies were performed using a Malvern Zetasizer Nano ZS instrument equipped with a He-Ne solid-state laser operating at $633 \mathrm{~nm}$ using back-scattered light at a scattering angle of $173^{\circ}$. Polymer dispersions

Table 1 Summary of PBzMA latexes synthesised via RAFT miniemulsion polymerisation with varying HD concentration at $70{ }^{\circ} \mathrm{C}$ for 240 min. The concentration of Lutensol TO 20 was fixed at $7.8 \% \mathrm{w} / \mathrm{w}$ relative to BzMA and [BzMA] : [PETTCCP] : [AIBN] $=300: 1: 2.3$

\begin{tabular}{llllllll}
\hline $\mathrm{HD}^{a} / \% \mathrm{w} / \mathrm{w}$ & Conversion $^{b} / \%$ & $M_{\mathrm{n}}{ }^{c} / \mathrm{kg} \mathrm{mol}^{-1}$ & $M_{\mathrm{w}} / M_{\mathrm{n}}{ }^{c}$ & $D_{\mathrm{h}}{ }^{d} / \mathrm{nm}$ & $N_{\mathrm{p}}{ }^{e} / \times 10^{14} \mathrm{~mL}^{-1}$ & $R_{\mathrm{P}} f_{/ \mathrm{M} \mathrm{s}^{-1}} R_{\mathrm{N}}{ }^{g} / \times 10^{-15} \mathrm{M} \mathrm{s}^{-1}$ \\
\hline 1.2 & 98.5 & 36.0 & 1.31 & $338(0.06)$ & 1.40 & 0.34 & 2.45 \\
2.4 & 98.9 & 36.5 & 1.27 & $330(0.12)$ & 1.50 & 0.34 & 2.30 \\
4.8 & 94.6 & 36.0 & 1.29 & $325(0.10)$ & 1.57 & 0.33 & 0.33 \\
7.2 & 95.8 & 34.2 & 1.29 & $299(0.07)$ & 2.02 & 1.65 & 0.33 \\
9.5 & 94.3 & 34.9 & 1.29 & $296(0.09)$ & 2.08 & 1.58
\end{tabular}

${ }^{a}$ Relative to BzMA monomer. ${ }^{b}$ Determined by gravimetry. ${ }^{c}$ Determined by THF GPC analysis. ${ }^{d}$ Obtained via DLS, PDI values are indicated in brackets. ${ }^{e}$ Calculated using eqn (S1) (ESI $\dagger$ ). ${ }^{f}$ Calculated using eqn (S2) (ESI $\dagger$ ). ${ }^{g}$ Calculated using eqn (S3) (ESI $\dagger$ ).

Table 2 Summary of PBzMA latexes synthesised via RAFT miniemulsion polymerisation with varying [PETTCCP] : [AIBN] ratio at $70{ }^{\circ} \mathrm{C}$ for 240 min. The target DP was 300 . Polymerisations were conducted at a dispersed phase content of $20 \% \mathrm{w} / \mathrm{w}$ with the concentration of HD and TO 20 fixed at $2.4 \% \mathrm{w} / \mathrm{w}$ and $7.8 \% \mathrm{w} / \mathrm{w}$ relative to $\mathrm{BzMA}$, respectively

\begin{tabular}{llllllll}
\hline [PETTCCP]: [AIBN] ratio & Conversion $^{a} / \%$ & $M_{\mathrm{n}}{ }^{b} / \mathrm{kg} \mathrm{mol}^{-1}$ & $M_{\mathrm{w}} / M_{\mathrm{n}}{ }^{b}$ & $D_{\mathrm{h}}{ }^{c} / \mathrm{nm}$ & $N_{\mathrm{p}}{ }^{d} / \times 10^{14} \mathrm{~mL}^{-1}$ & $R_{\mathrm{P}}{ }^{e} / \mathrm{M} \mathrm{s}^{-1}$ & $R_{\mathrm{N}}{ }^{f} / \times 10^{-15} \mathrm{M} \mathrm{s}^{-1}$ \\
\hline 10 & 60.0 & 24.3 & 1.33 & $268(0.08)$ & 2.91 & 0.21 & 0.72 \\
5 & 91.8 & 36.7 & 1.28 & $306(0.15)$ & 1.88 & 0.32 & 1.70 \\
2 & 96.4 & 37.0 & 1.28 & $311(0.08)$ & 1.78 & 0.34 & 1.89 \\
1 & 98.5 & 38.2 & 1.25 & $303(0.11)$ & 1.93 & 0.34 & 1.78 \\
0.4 & 98.9 & 36.5 & 1.27 & $330(0.12)$ & 1.50 & 0.34 & 2.30
\end{tabular}

${ }^{a}$ Determined via gravimetry. ${ }^{b}$ Determined by THF GPC analysis. ${ }^{c}$ Obtained via DLS, where PDI values are indicated in brackets. ${ }^{d}$ Calculated using eqn (S1) (ESI $\dagger$ ). ${ }^{e}$ Calculated using eqn (S2) (ESI $\dagger$ ). ${ }^{f}$ Calculated using eqn (S3) (ESI $\dagger$ ).

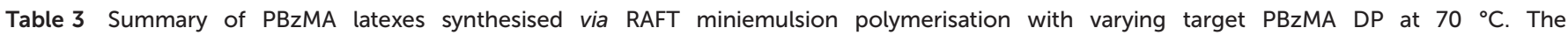

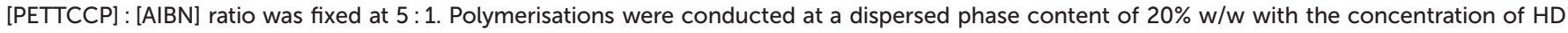
and TO 20 fixed at $2.4 \% \mathrm{w} / \mathrm{w}$ and $7.8 \% \mathrm{w} / \mathrm{w}$ relative to BzMA, respectively

\begin{tabular}{|c|c|c|c|c|c|c|c|c|c|}
\hline Target PBzMA DP & $\begin{array}{l}{[\text { PETTCCP }]^{a} /} \\
\text { mmol L }^{-1}\end{array}$ & $\begin{array}{l}\text { Reaction } \\
\text { time/min }\end{array}$ & $\begin{array}{l}\text { Conversion }^{b} / \\
\%\end{array}$ & $\begin{array}{l}M_{\mathrm{n}}{ }^{c} / \\
\mathrm{kg} \mathrm{mol}^{-1}\end{array}$ & $\begin{array}{l}M_{\mathrm{w}} / \\
M_{\mathrm{n}}{ }^{c}\end{array}$ & $D_{\mathrm{h}}^{d} / \mathrm{nm}$ & $\begin{array}{l}N_{\mathrm{p}}^{e} / \\
\times 10^{14} \mathrm{~mL}^{-1}\end{array}$ & $\begin{array}{l}R_{\mathrm{P}}{ }^{f /} \\
\mathrm{M} \mathrm{s}^{-1}\end{array}$ & $\begin{array}{l}R_{\mathrm{N}}^{g} / \\
\times 10^{-15} \mathrm{M} \mathrm{s}^{-1}\end{array}$ \\
\hline 200 & 28.6 & 240 & 96.3 & 25.4 & 1.24 & $330(0.12)$ & 1.49 & 0.34 & 2.25 \\
\hline 300 & 19.1 & 240 & 91.8 & 36.7 & 1.28 & $306(0.15)$ & 1.88 & 0.32 & 1.70 \\
\hline 400 & 14.3 & 240 & 84.9 & 43.8 & 1.27 & $291(0.09)$ & 2.18 & 0.30 & 1.36 \\
\hline 700 & 8.2 & 360 & 96.5 & 78.4 & 1.29 & $281(0.07)$ & 2.67 & 0.22 & 0.84 \\
\hline 800 & 7.1 & 360 & 90.4 & 78.9 & 1.31 & $275(0.10)$ & 2.84 & 0.21 & 0.74 \\
\hline
\end{tabular}

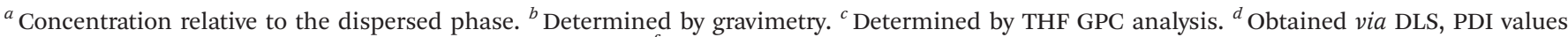
are indicated in brackets. ${ }^{e}$ Calculated using eqn (S1) (ESI $\dagger$ ). ${ }^{f}$ Calculated using eqn (S2) (ESI $\dagger$ ). ${ }^{g}$ Calculated using eqn (S3) (ESI $\dagger$ ). 
without any purification were diluted to approximately $0.1 \%$ w/w using deionised water. Samples were analysed using disposable plastic cuvettes at $25^{\circ} \mathrm{C}$. Data were averaged over three consecutive measurements.

Molar mass distributions were assessed using a gel permeation chromatography (GPC) instrument equipped with an Agilent 1260 Infinity pump injection module, an Agilent 1260 Infinity II refractive index detector, and three Phenomenex phenogel columns with a mobile phase of THF at $35{ }^{\circ} \mathrm{C}$. Calibration was achieved using a series of polystyrene standards (ranging from $1 \times 10^{3}$ to $2 \times 10^{6} \mathrm{~g} \mathrm{~mol}^{-1}$ ).

Transmission electron microscopy (TEM) images were recorded using a FEI Tecnai G2 20 instrument operating at an accelerating voltage of $200 \mathrm{kV}$ and connected to a Gatan $1 \mathrm{k}$ CCD camera. Samples for TEM observation were prepared by depositing $3 \mu \mathrm{L}$ of diluted copolymer dispersion (approximately $0.1 \% \mathrm{w} / \mathrm{w}$ ) onto 400 mesh carbon-coated copper grids for $30 \mathrm{~min}$ and then carefully blotted using filter paper to remove excess solution. The samples were stained in a vapour space above ruthenium tetroxide $\left(\mathrm{RuO}_{4}\right)$ solution at room temperature for $7 \mathrm{~min}^{77}$ Mean nanoparticle diameters were determined using ImageJ software and over 200 randomly selected particles were measured for each sample.

\section{Results and discussion}

Surfactant selection for miniemulsion polymerisation of BzMA

In order to ascertain a suitable surfactant for miniemulsion polymerisation of BzMA, several surfactants were screened by monitoring the stability of BzMA miniemulsion droplets obtained after ultrasonication. A conventional ionic surfactant (SDS) and a series of Lutensol TO non-ionic surfactants, including TO 3 , TO 8 , TO 15 , TO 20 , and TO 109 , were evaluated. All of these surfactants allowed the formation of BzMA miniemulsions, which remained stable over the timescale of a typical miniemulsion polymerisation. However, Lutensol TO 20 formed emulsions that were stable for the longest period of time (over 11 days) and thus was chosen as the optimal non-ionic surfactant from this range to investigate further.

Fig. S1 (ESI†) shows critical micelle concentrations (CMC) determined using pendant drop analysis of interfacial tension for SDS and Lutensol TO 20 in deionised water. The CMC for SDS was approximately $9.2 \mathrm{mM}$, which is in agreement with the literature $(\sim 8 \mathrm{mM}) \cdot{ }^{78,79}$ In contrast, the CMC of TO 20 $(\sim 0.5 \mathrm{mM})$ was much lower than that of SDS, indicating that TO 20 can act as a more efficient emulsifier. ${ }^{80,81}$

The difference in diameter between the emulsified droplets and resulting latexes can be used to indicate polymerisation type. For example, if the resulting latex size is significantly smaller than the monomer reservoir droplets, it can be classified as emulsion polymerisation. Whereas if the resulting latex is equal in diameter to the initial droplets, it is classified as miniemulsion polymerisation. ${ }^{82,83}$ A $1: 1$ transfer from initial droplets to latexes is possible only when using a suitable sur- factant for emulsification in the appropriate concentration range. ${ }^{83}$ However, the surfactant concentration used in a miniemulsion formulation is generally above the CMC determined in deionised water. This is because the majority of surfactant molecules locate at the monomer/water droplet interface after the emulsification step. ${ }^{36}$ Therefore, only a small proportion of surfactant molecules dissolve in the continuous phase, meaning the continuous phase surfactant concentration is actually lower than CMC. This prevents micellar nucleation. ${ }^{84,85}$ For example, Landfester and coworkers reported poly(methyl methacrylate) latexes synthesised via miniemulsion polymerisation using SDS surfactant at concentrations up to $40 \mathrm{mM}$, which is much higher than the CMC for SDS in pure deionised water $(\sim 8 \mathrm{mM}) .{ }^{36,82}$ The same research group also demonstrated that polystyrene latexes can be synthesised via miniemulsion polymerisation using $0.5-50 \% \mathrm{w} / \mathrm{W}$ SDS surfactant relative to monomer. ${ }^{84}$

A series of experiments were conducted using a relatively wide range of surfactant concentrations to determine the optimal conditions for miniemulsion polymerisation of BzMA. Fig. S2 and S3 (ESI $\dagger$ ) show the evolution of hydrodynamic diameter as a function of time for conventional free-radical miniemulsion polymerisation of BzMA using a range of SDS anionic surfactant and HD hydrophobe concentrations. In most cases, the final PBzMA latex diameter was significantly smaller than the initial miniemulsion droplets. This indicated that regular emulsion polymerisation was taking place as opposed to miniemulsion polymerisation. Fig. S4 (ESI $\dagger$ ) shows the mean-diameter of PBzMA latexes synthesised using a wide range of TO 20 non-ionic surfactant concentrations. At surfactant concentrations below $0.5 \% \mathrm{w} / \mathrm{w}$, a relatively large difference between the monomer droplet and final latex diameters were observed. Above $7.8 \% \mathrm{w} / \mathrm{w}$ surfactant, sub-micron latexes were obtained which had diameters similar to the initial droplet diameter, indicating successful miniemulsion conditions. On increasing the surfactant concentration from 0.1 to $23.3 \% \mathrm{w} / \mathrm{w}$, the mean latex diameter decreased from approximately 2400 to $164 \mathrm{~nm}$. As expected, higher surfactant concentrations resulted in smaller polymer particles due to the lower surface tension of the system. ${ }^{84}$ It is noteworthy that the sub$500 \mathrm{~nm}$ latexes which had a similar diameter to the initial droplet size were achieved using a TO 20 concentration $\geq 7.8 \%$ $\mathrm{w} / \mathrm{w}$ (or $\geq 19 \mathrm{mM}$ ). This concentration was approximately 38 times greater than the CMC determined in deionised water $(\sim 0.5 \mathrm{mM})$. Given the suitability of Lutensol TO 20 for miniemulsion polymerisation of BzMA, this surfactant was utilised in all subsequent miniemulsion polymerisations reported herein.

\section{Comparison of conventional free-radical miniemulsion polymerisation with RAFT-mediated miniemulsion polymerisation}

Miniemulsion polymerisation of BzMA was conducted in the presence of two RAFT CTAs (PETTC and PETTCCP, target DP = 300, see Fig. 1 for chemical structures) and without a CTA under otherwise identical conditions. It was observed that 


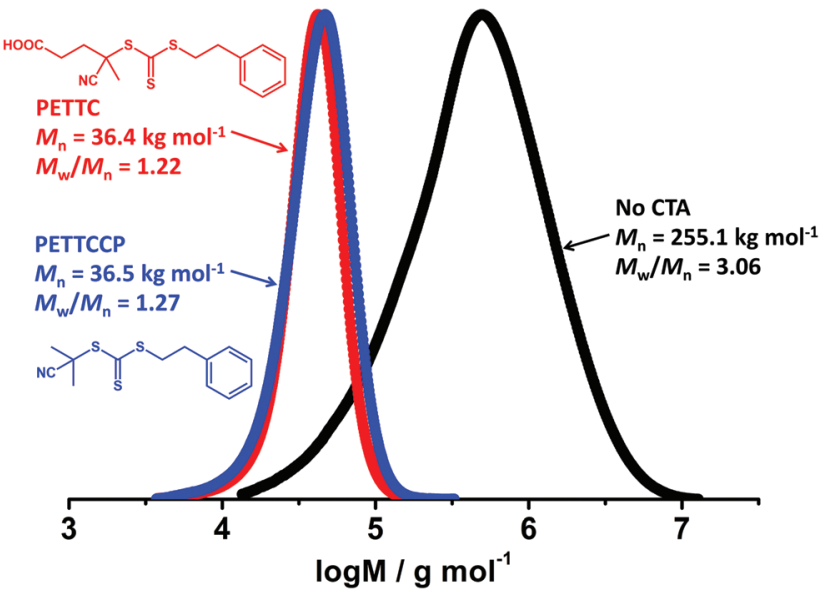

Fig. 1 GPC chromatograms for PBzMA synthesised via RAFT miniemulsion polymerisation in the presence of no CTA (black), PETTC (red) and PETTCCP (blue) at $70{ }^{\circ} \mathrm{C}$. The target PBzMA degree of polymerisation (DP) in the presence of RAFT CTAs was 300 and [CTA]/[AIBN] was 0.4 . Polymerisations were conducted at a dispersed phase content of $20 \% \mathrm{w} / \mathrm{w}$ with the concentration of HD and TO 20 fixed at $2.4 \% \mathrm{w} / \mathrm{w}$ and $7.8 \% \mathrm{w} / \mathrm{w}$ relative to BzMA, respectively. Monomer conversions using no CTA, PETTC, and PETTCCP CTA were $99.9 \%$, 97.3\%, and $99.6 \%$, respectively (Table S2, ESI $\dagger$ ).

PBzMA latexes synthesised via conventional free-radical miniemulsion polymerisation achieved full monomer conversion within 40 min (Fig. S5a, ESI $†$ ) whereas the two RAFT-mediated reactions took approximately $60-100 \mathrm{~min}$ to reach full conversion. Furthermore, the molar mass of PBzMA was much higher and the molar mass distribution was broader $\left(M_{\mathrm{w}} / M_{\mathrm{n}}>3.0\right)$ in the absence of a CTA than for the polymers synthesised using the RAFT CTAs (Fig. 1, Fig. S5b and Table S2, ESI†). This indicates that RAFT control over BzMA polymerisation was achieved in the presence of both PETTC and PETTCCP RAFT agents.

The mean particle diameter of PBzMA latexes prepared with no CTA and using PETTCCP were $338 \mathrm{~nm}$ and $325 \mathrm{~nm}$, respectively. However, the particle diameter was significantly higher $(577 \mathrm{~nm})$ when using PETTC. This can be attributed to the PETTC being more hydrophilic than PETTCCP and thus having an increased ability to cross into the aqueous phase. Therefore, PETTC may form a surfactant/cosurfactant structure at the droplet-water interface and lead to an increased particle diameter. ${ }^{33}$ Nevertheless, the minor difference in particle diameter observed for PBzMA latexes prepared by conventional miniemulsion polymerisation and using PETTCCP, as well as the increased control over polymer molar mass afforded, indicates the suitability of PETTCCP for RAFT-mediated miniemulsion polymerisation of BzMA. Thus, the influence of hydrophobe, initiator and CTA concentration were investigated further.

\section{Influence of hydrophobe concentration}

The use of a small quantity of HD as a hydrophobe allows the build-up of osmotic pressure in miniemulsion droplets, pro- viding stability against Ostwald ripening. ${ }^{86}$ Thus the influence of HD concentration on RAFT miniemulsion polymerisation of BzMA was investigated by varying the HD concentration between $1.2-9.5 \% \mathrm{w} / \mathrm{w}$, based on BzMA, while the concentration of monomer, initiator, surfactant, and CTA remained unchanged (see Table 1). With increasing HD concentration, the measured PBzMA latex diameter $\left(D_{\mathrm{h}}\right)$ decreases from 338 to $296 \mathrm{~nm}$, corresponding to a calculated increase in the number of particles per unit volume $\left(N_{\mathrm{p}}\right)$. This indicates that with higher HD concentrations, more droplets can be stabilised against Ostwald ripening effects and the average droplet size decreases. However, the influence of HD on polymerisation kinetics was negligible with high monomer conversions being achieved in all cases within 60 min (Fig. 2a). Similarly, no significant differences in PBzMA molar mass evolution were observed (Fig. 2b), with the final latexes having relatively consistent molar masses and molar mass distributions (Table 1). These observations suggest that these miniemulsion polymerisations were under good RAFT control. Furthermore, there was no obvious influence of HD concentration on the overall polymerisation rate (Table 1). However, due to the
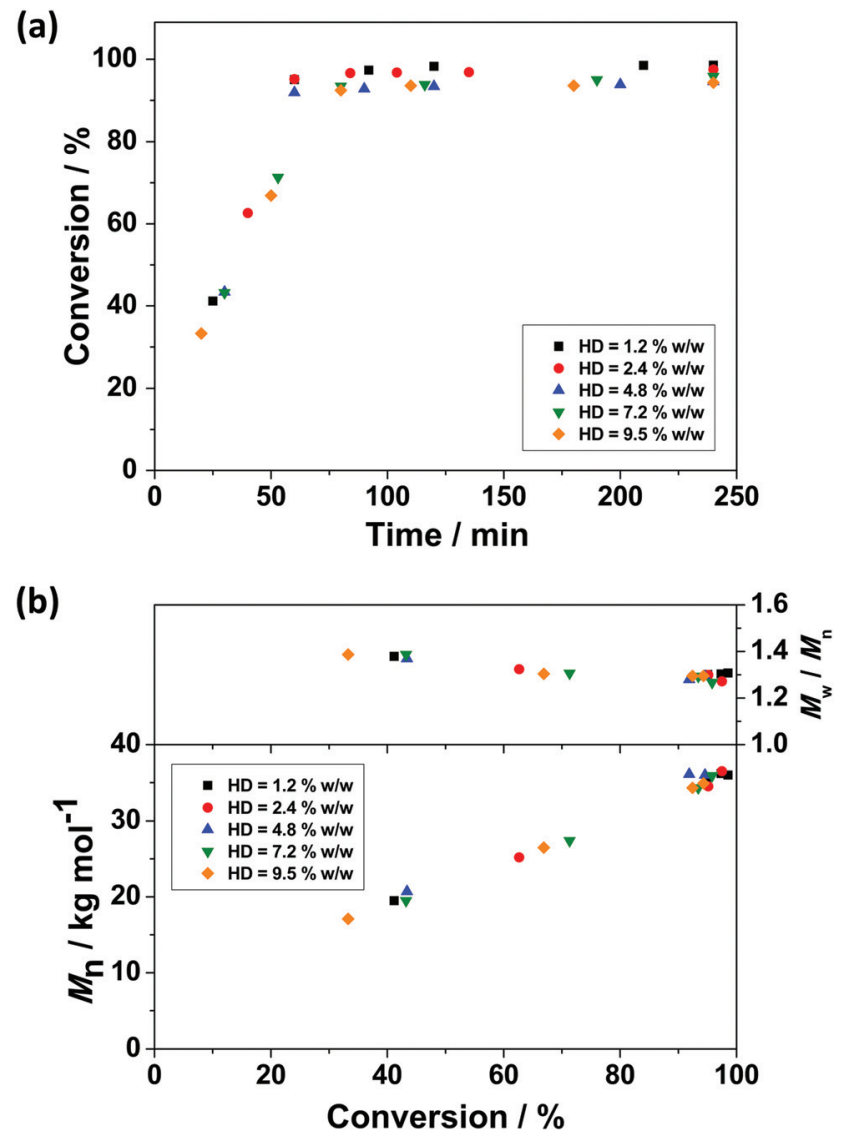

Fig. 2 (a) Monomer conversion versus reaction time and (b) $M_{\mathrm{n}}$ and $M_{\mathrm{w}} / M_{\mathrm{n}}$ versus monomer conversion for PBzMA synthesised via RAFT miniemulsion polymerisation with varying $H D$ concentration relative to BzMA at $70{ }^{\circ} \mathrm{C}$. [BzMA] : [PETTCCP] : [AIBN] $=300: 1: 2.3$ and the concentration of TO 20 surfactant was fixed at $7.8 \% \mathrm{w} / \mathrm{w}$ relative to BzMA. 
increased number of particles generated with more HD, the mean polymerisation rate per particle $\left(R_{\mathrm{N}}\right)$ decreased with increasing HD concentration (Table 1 and Fig. S6, ESI†े).

\section{Influence of initiator concentration}

The influence of initiator concentration was investigated by varying the $[\mathrm{PETTCCP}]:[\mathrm{AIBN}]$ ratio whilst keeping the concentration of monomer, hydrophobe, surfactant, and chain transfer agent constant (Table 2). In most cases, $>90 \%$ monomer conversion was achieved after 240 min (Fig. 3a). Furthermore, increasing the amount of initiator increases the overall rate of polymerisation and follows a power-law relationship $R_{\mathrm{p}} \alpha$ $[\mathrm{AIBN}]^{1 / 2} \cdot{ }^{87-89}$ Fig. $3 \mathrm{~b}$ shows the approximately linear relationship between $\ln \left([M]_{0} /[M]\right)$ and reaction time, indicating the polymerisations were first-order with respect to monomer concentration. ${ }^{54}$ Fig. $3 \mathrm{c}$ shows the evolution of molar mass and molar mass dispersity $\left(M_{\mathrm{w}} / M_{\mathrm{n}}\right)$ versus monomer conversion. It is noteworthy that unlike the polymerisation rate, which was strongly influenced by the initiator concentration, there were negligible differences in the observed molar mass and molar mass dispersity values.

The relatively linear conversion/time relationships and the pseudo-first-order kinetic plots (Fig. 3) are reasonably consistent with the features expected for a controlled RAFT polymerisation. This indicates that a rapid main equilibrium between the active propagating radicals and thiocarbonylthio capped dormant species was achieved and a constant number of radical propagating chains was formed during polymerisation. ${ }^{88}$ Additionally, no obvious retardation in these formulations was observed and polymerisations proceeded linearly to high monomer conversions ( $90 \%$ after 240 min, Fig. 3a). In all cases, the evolution of molar mass in relation to monomer conversion was close to linear, with relatively narrow molar mass dispersities obtained $\left(M_{\mathrm{w}} / M_{\mathrm{n}}<1.3\right)$. It is noteworthy that positive y-intercepts were observed in all cases after extrapolating the experimental data for $M_{\mathrm{n}}$ to zero conversion. Differences between the GPC calibration standards (polystyrene) and PBzMA may be partially the cause of this positive intercept and deviations from theoretical $M_{\mathrm{n}}$ values.

However, the observed positive y-intercepts may also result from a higher polymerisation rate than that of the addition of growing radicals to the PETTCCP CTA. ${ }^{90,91}$ Therefore, RAFT control was not established instantaneously, resulting in the rapid formation of moderate molar mass species at low monomer conversions. These observations may be considered as hybrid conventional/living behaviour. ${ }^{92-94}$ However, this behaviour can be reduced by using a lower ratio of [CTA] to [initiator]. ${ }^{91}$ For example, the y-intercept was approximately $9 \mathrm{~kg} \mathrm{~mol}^{-1}$ when the [CTA]:[initiator] ratio was $5: 1$ whereas the y-intercept was approximately $2 \mathrm{~kg} \mathrm{~mol}^{-1}$ ( 78\% less) when the ratio was 0.4. This indicates that higher initiator concentrations allow more rapid CTA activation, resulting in a shorter time in achieving the main RAFT equilibrium. Nevertheless, the molar mass dispersities of the resultant polymers were relatively low, suggesting this hybrid behaviour had a minor effect on the overall RAFT process.
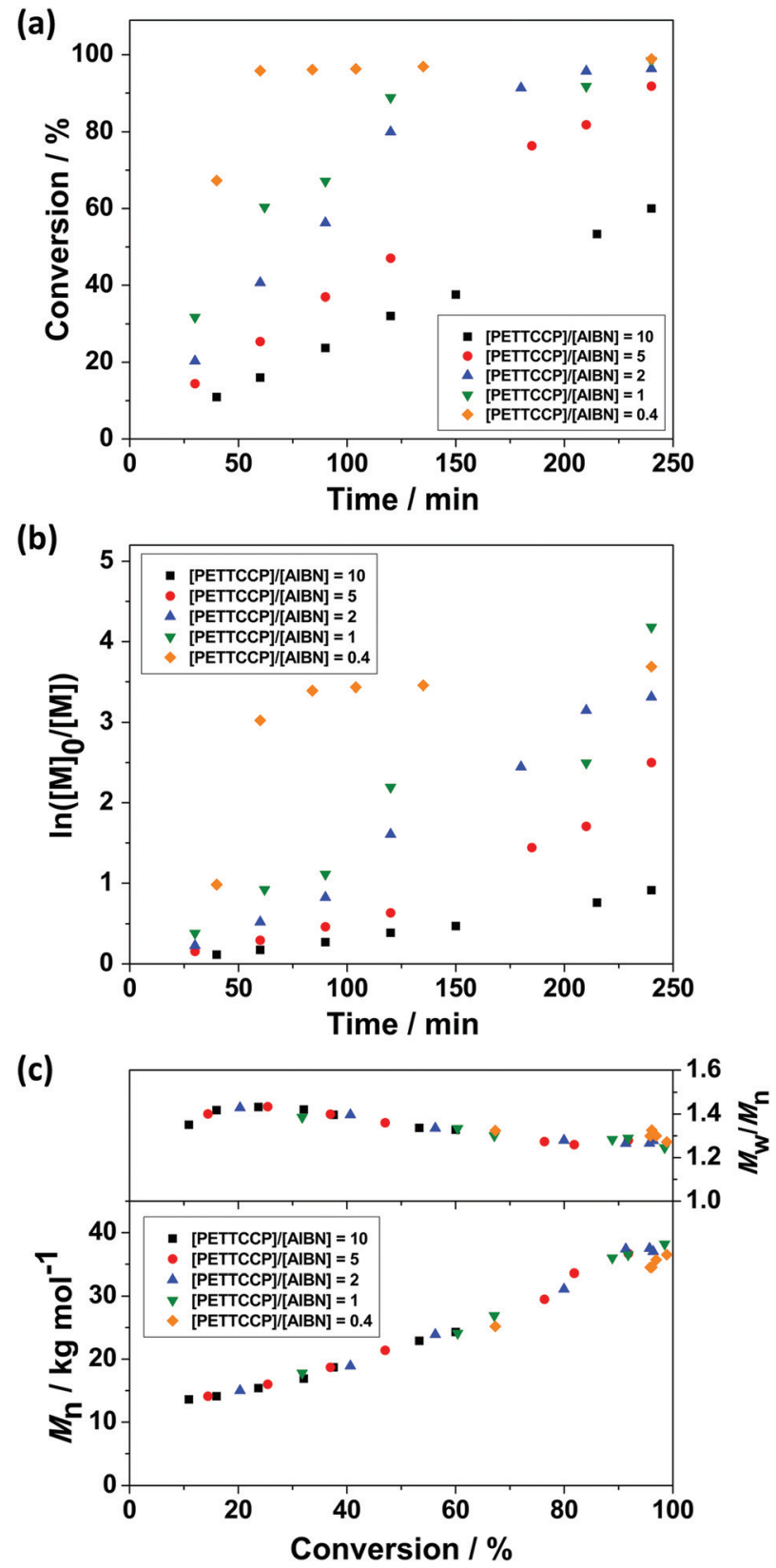

Fig. 3 (a) Monomer conversion versus reaction time, (b) semi-logarithmic kinetics, and (c) $M_{\mathrm{n}}$ and $M_{\mathrm{w}} / M_{\mathrm{n}}$ versus monomer conversion for PBzMA synthesised via RAFT miniemulsion polymerisation at $70{ }^{\circ} \mathrm{C}$ with varying [PETTCCP] : [AIBN] ratio. The target DP was 300 . Polymerisations were conducted at a dispersed phase content of $20 \% \mathrm{w} / \mathrm{w}$, with the concentration of $\mathrm{HD}$ and TO 20 fixed at $2.4 \% \mathrm{w} / \mathrm{w}$ and $7.8 \% \mathrm{w} / \mathrm{w}$ relative to $B z M A$, respectively.

\section{Influence of RAFT agent concentration}

The versatility and limitations of RAFT-mediated miniemulsion polymerisation of BzMA were further investigated by varying the PETTCCP concentration. Specifically, the molar concentration of PETTCCP relative to the dispersed phase was varied from $7.1 \mathrm{mmol} \mathrm{L}^{-1}$ (target PBzMA DP $=800$ ) to $28.6 \mathrm{mmol} \mathrm{L}^{-1}($ target PBzMA DP $=200)$. A [PETTCCP] : [AIBN] 
ratio of 5:1 was used whilst keeping the concentration of monomer, hydrophobe, and surfactant constant (Table 3). High monomer conversions ( 90\%) were achieved after $240 \mathrm{~min}$ (for DP 200, 300, and 400) or $360 \mathrm{~min}$ (for DP 700 and 800, Fig. 4a). Interestingly, the polymerisation rate increased with increasing PETTCCP concentration (or decreasing target DP). For example, the polymerisation rate for PETTCCP at $28.6 \mathrm{mmol} \mathrm{L}^{-1}$ relative to the dispersed phase (DP $=200$ ) was approximately $62 \%$ faster than for PETTCCP at $7.1 \mathrm{mmol} \mathrm{L}^{-1}(\mathrm{DP}=800)$ (Table 3$)$. In this study, the [CTA]: [initiator] ratio was fixed at $5: 1$. Thus, increased RAFT CTA concentrations (lower target DP) also meant that the initiator concentration relative to BzMA was also higher. This inevitably led to the faster polymerisation rates observed for lower target DP formulations. It is noteworthy that the rate of polymerisation observed was relatively independent of droplet diameter and rate increases due to compartmentalisation effects were not observed. This can be attributed to the latexes in this work being relatively large $(\sim 300 \mathrm{~nm}) .^{32,95,96}$

$\ln \left([M]_{0} /[M]\right)$ versus reaction time for these RAFT miniemulsion polymerisations is shown in Fig. 4b. The approximately linear relationship in all cases indicates that the reactions were first-order with respect to monomer concentration and thus were well-controlled RAFT polymerisations. ${ }^{54}$ GPC chromatograms of PBzMA synthesised with various PETTCCP concentrations at full monomer conversion are shown in Fig. 4d. Unimodal and relatively narrow molar mass distributions $\left(M_{\mathrm{w}} / M_{\mathrm{n}}<1.3\right)$ were obtained in all cases, with the $M_{\mathrm{n}}$ clearly increasing with decreasing RAFT agent concentration. The evolution of molar mass and molar mass dispersity $\left(M_{\mathrm{w}} / M_{\mathrm{n}}\right)$ versus monomer conversion for PBzMA with various PETTCCP concentrations (target DP 200-800) are shown in Fig. 4c. As the polymerisations progressed, the corresponding dispersity decreased, and the resulting PBzMA had relatively narrow molar mass distributions $\left(M_{\mathrm{w}} / M_{\mathrm{n}}<1.3\right)$ at $90 \%$ conversion. It is noteworthy that the molar mass increased approximately linear in all cases, even when targeting high DPs.

The measured PBzMA latex diameter $\left(D_{\mathrm{h}}\right)$ decreased from 330 to $275 \mathrm{~nm}$ with increasing PETTCCP concentration (Fig. 5). This corresponded to a calculated increase in the number of particles per unit volume $\left(N_{\mathrm{p}}\right)$ from approximately 1.5 to $2.8 \times 10^{14} \mathrm{~mL}^{-1}$. Furthermore, spherical latexes were obtained in all cases with measured diameters in agreement between TEM and DLS (Fig. 6 and Table 3). It is noteworthy that the number of particles $\left(N_{\mathrm{p}}\right)$ decreased with increasing RAFT agent concentration (Fig. 5). For example, the $N_{\mathrm{p}}$ value for PETTCCP at $28.6 \mathrm{mmol} \mathrm{L}^{-1}$ was approximately $48 \%$ less than PETTCCP at $7.1 \mathrm{mmol} \mathrm{L}^{-1}$. This is attributed to the increased viscosity of the oil phase. ${ }^{97}$ More specifically, formulations with higher PETTCCP concentrations result in droplets which are more viscous. Thus, fewer droplets are produced using the same ultrasonication procedure and results in larger miniemulsion droplets and final PBzMA latexes.

Finally, PBzMA chain-end stability and fidelity over a 12-month storage period was examined via self-blocking experiments (Fig. S7, ESI $\dagger$ ). After being stored at room temp- (a)
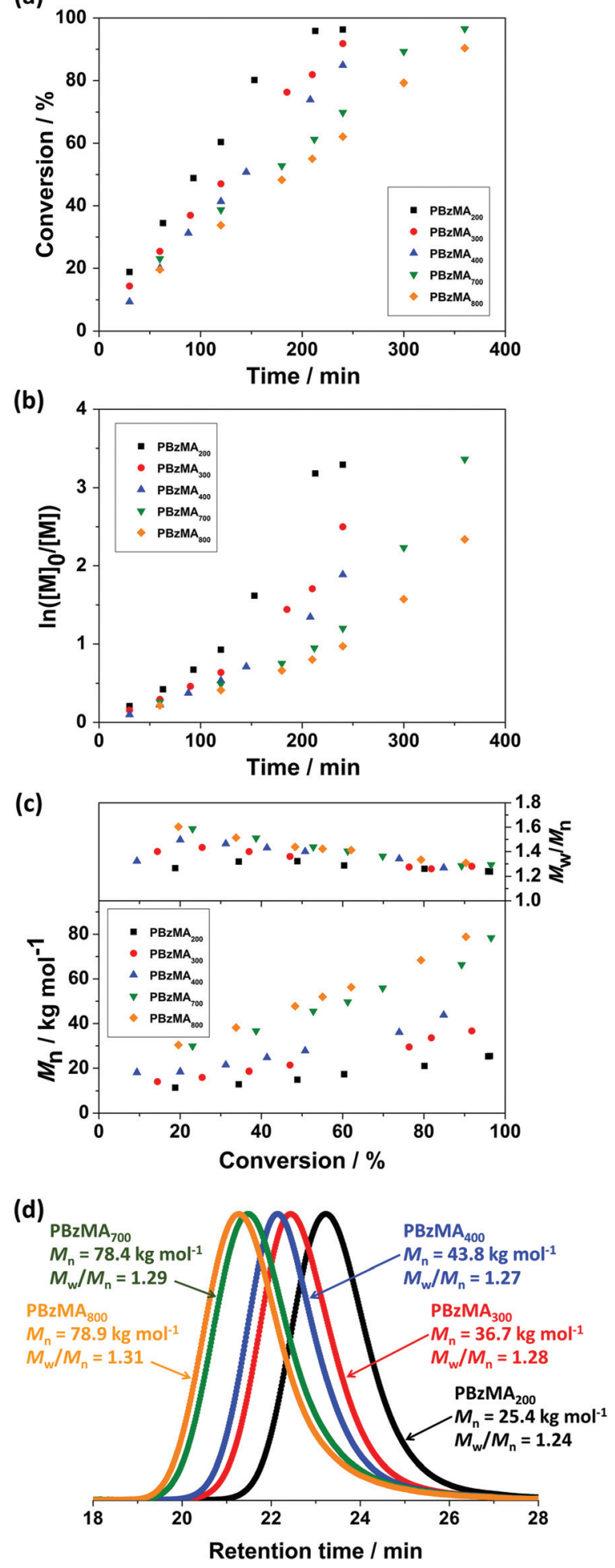

Fig. 4 (a) Monomer conversion versus reaction time, (b) semi-logarithmic kinetics, (c) $M_{n}$ and $M_{w} / M_{n}$ versus monomer conversion, and (d) GPC chromatograms for PBzMA synthesised via RAFT miniemulsion polymerisation with varying target DP at $70{ }^{\circ} \mathrm{C}$. The [PETTCCP] : [AIBN] ratio was fixed at $5: 1$ and polymerisations were conducted at a dispersed phase content of $20 \% \mathrm{w} / \mathrm{w}$, with the concentration of $\mathrm{HD}$ and TO 20 fixed at $2.4 \% \mathrm{w} / \mathrm{w}$ and $7.8 \% \mathrm{w} / \mathrm{w}$ relative to BzMA, respectively. 


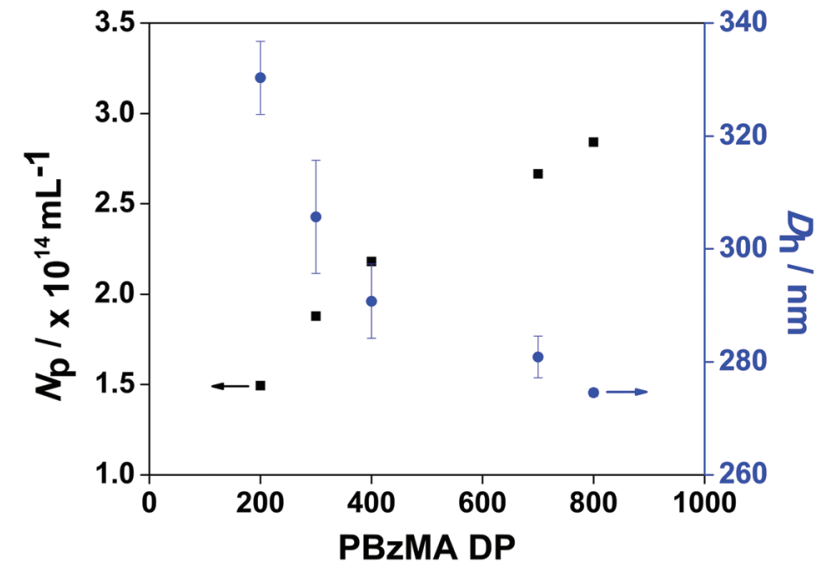

Fig. 5 Effect of varying target PBzMA DP on the number of particles $\left(N_{\mathrm{p}}\right)$ for PBzMA synthesised via RAFT miniemulsion polymerisation at $70{ }^{\circ} \mathrm{C}$. The [PETTCCP] : [AIBN] ratio was fixed at $5: 1$ and polymerisations were conducted at a dispersed phase content of $20 \% \mathrm{w} / \mathrm{w}$, with the concentration of HD and TO 20 fixed at $2.4 \% \mathrm{w} / \mathrm{w}$ and $7.8 \% \mathrm{w} / \mathrm{w}$ relative to BzMA, respectively.
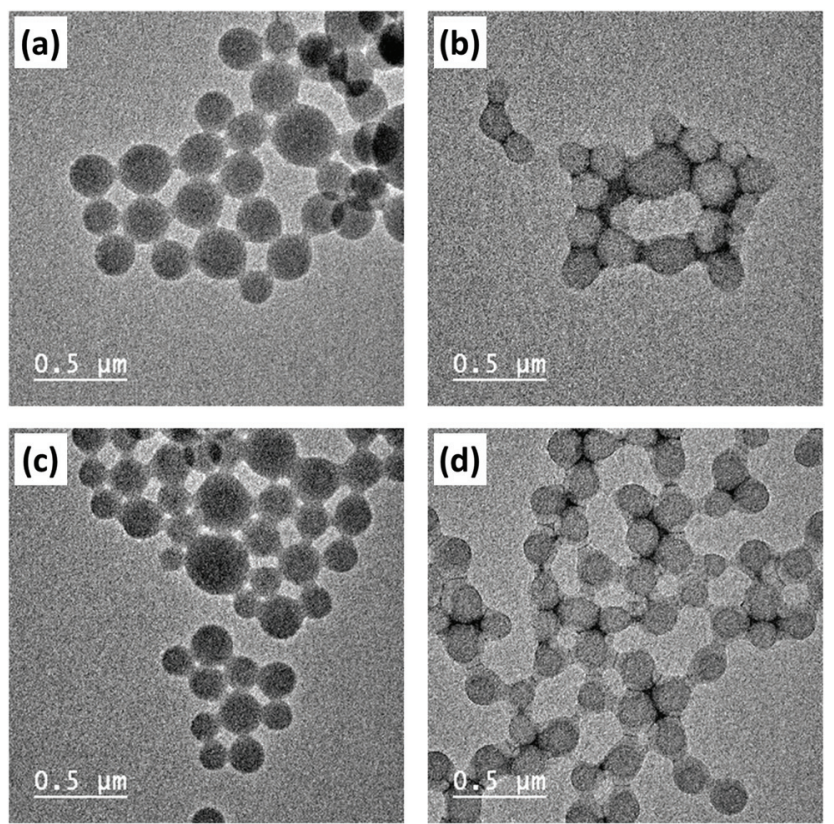

Fig. 6 Representative TEM images for PBzMA latexes synthesised via RAFT miniemulsion polymerisation at $70{ }^{\circ} \mathrm{C}$ with varying target DP: (a) 200, (b) 300, (c) 700, and (d) 800 . The [PETTCCP] : [AIBN] ratio was fixed at $5: 1$ and polymerisations were conducted at a dispersed phase content of $20 \% \mathrm{w} / \mathrm{w}$, with the concentration of HD and TO 20 fixed at $2.4 \% \mathrm{w} / \mathrm{w}$ and $7.8 \% \mathrm{w} / \mathrm{w}$ relative to $\mathrm{BzMA}$, respectively.

erature for over a year, an additional charge of BzMA (target DP of second block $=300$ ) and initiator was added to a dispersion of PBzMA latex (Table 2, entry 3). GPC analysis indicated a relatively good blocking efficiency and the resulting chain-extended PBzMA homopolymer had a unimodal molar mass distribution and relatively low molar mass dispersity (1.39). This indicates that the majority of the trithiocarbonate
RAFT chain-ends remained intact and that these PBzMA latexes could undergo efficient chain extension to form second blocks with other monomers to form more complex latex morphologies. $^{98,99}$

\section{Conclusions}

Near-monodisperse PBzMA latexes with controlled particle diameters and polymer molar mass were successfully prepared via RAFT miniemulsion polymerisation. This was achieved using a relatively hydrophobic chain transfer agent (PETTCCP) and non-ionic Lutensol TO 20 surfactant. Stable miniemulsion droplets were obtained and formed PBzMA latexes upon polymerisation. Much narrower molar mass distributions $\left(M_{\mathrm{w}} / M_{\mathrm{n}}\right.$ < 1.3) were obtained via RAFT miniemulsion polymerisation when compared to conventional miniemulsion polymerisation $\left(M_{\mathrm{w}} / M_{\mathrm{n}}>3.0\right)$. Furthermore, the concentration of hydrophobe, initiator, and chain transfer agent were demonstrated to influence the particle diameter, particle number, rate of polymerisation, and PBzMA molar mass in the final latexes.

Increasing the hydrophobe (HD) concentration decreased the PBzMA latex diameter $\left(D_{\mathrm{h}}\right)$ and increased the number of particles per unit volume $\left(N_{\mathrm{p}}\right)$. This indicated that more droplets can be stabilised against Ostwald ripening effects using higher HD concentrations. Furthermore, the mean rate per particle decreased with increasing HD concentration. Increasing initiator (AIBN) concentration increased the overall rate of polymerisation and followed a power-law relationship $R_{\mathrm{p}} \propto[\mathrm{AIBN}]^{1 / 2}$. However, only negligible differences in molar mass, molar mass dispersity, and particle diameter values were observed. Increasing RAFT agent (PETTCCP) concentration increased the measured PBzMA latex diameter $\left(D_{\mathrm{h}}\right)$ and the overall rate of polymerisation. The changes in latex diameter can be attributed to the increased viscosity of the oil phase, which results in larger miniemulsion droplets. Furthermore, the approximately linear relationship of ln $\left([M]_{0} /[M]\right)$ versus reaction time, unimodal GPC chromatograms, relatively narrow molar mass distributions $\left(M_{\mathrm{w}} / M_{\mathrm{n}}<1.3\right)$ and efficient self-blocking indicated that these were well-controlled RAFT miniemulsion polymerisations.

\section{Conflicts of interest}

There are no conflicts to declare.

\section{Acknowledgements}

National Chung-Shan Institute of Science and Technology (NCSIST) is thanked for funding a PhD studentship for SPW. EPSRC grant EP/P026095/2 is acknowledged for providing the ultrasonic processor. The University of Manchester Electron Microscopy Centre is acknowledged for access to electron microscopy facilities. This work was supported by the Henry Royce Institute for Advanced Materials, funded through EPSRC 
grants EP/R00661X/1, EP/S019367/1, EP/P025021/1 and $\mathrm{EP} / \mathrm{P} 025498 / 1$.

\section{Notes and references}

1 J. Qiu, B. Charleux and K. Matyjaszewski, Prog. Polym. Sci., 2001, 26, 2083-2134.

2 M. F. Cunningham, Prog. Polym. Sci., 2002, 27, 10391067.

3 N. Corrigan, K. Jung, G. Moad, C. J. Hawker, K. Matyjaszewski and C. Boyer, Prog. Polym. Sci., 2020, 101311.

4 G. Moad, E. Rizzardo and D. H. Solomon, Macromolecules, 1982, 15, 909-914.

5 M. K. Georges, R. P. Veregin, P. M. Kazmaier and G. K. Hamer, Macromolecules, 1993, 26, 2987-2988.

6 C. J. Hawker, A. W. Bosman and E. Harth, Chem. Rev., 2001, 101, 3661-3688.

7 J.-S. Wang and K. Matyjaszewski, J. Am. Chem. Soc., 1995, 117, 5614-5615.

8 K. Matyjaszewski, S. Gaynor and J.-S. Wang, Macromolecules, 1995, 28, 2093-2095.

9 J. Chiefari, Y. Chong, F. Ercole, J. Krstina, J. Jeffery, T. P. Le, R. T. Mayadunne, G. F. Meijs, C. L. Moad and G. Moad, Macromolecules, 1998, 31, 5559-5562.

10 G. Moad, J. Chiefari, Y. K. Chong, J. Krstina, R. T. A. Mayadunne, A. Postma, E. Rizzardo and S. H. Thang, Polym. Int., 2000, 49, 993-1001.

11 Y. Kwak, A. Goto, Y. Tsujii, Y. Murata, K. Komatsu and T. Fukuda, Macromolecules, 2002, 35, 3026-3029.

12 M. J. Monteiro and H. de Brouwer, Macromolecules, 2001, 34, 349-352.

13 P. B. Zetterlund, Y. Kagawa and M. Okubo, Chem. Rev., 2008, 108, 3747-3794.

14 M. F. Cunningham, Prog. Polym. Sci., 2008, 33, 365-398.

15 B. Charleux, G. Delaittre, J. Rieger and F. D'Agosto, Macromolecules, 2012, 45, 6753-6765.

16 P. B. Zetterlund, S. C. Thickett, S. Perrier, E. Bourgeat-Lami and M. Lansalot, Chem. Rev., 2015, 115, 9745-9800.

17 R. G. Gilbert, Emulsion polymerization: a mechanistic approach, Academic Pr, 1995.

18 J. Vosloo, D. De Wet-Roos, M. Tonge and R. Sanderson, Macromolecules, 2002, 35, 4894-4902.

19 S. W. Prescott, M. J. Ballard, E. Rizzardo and R. G. Gilbert, Aust. J. Chem., 2002, 55, 415-424.

20 M. Lansalot, T. P. Davis and J. P. Heuts, Macromolecules, 2002, 35, 7582-7591.

21 K. Matyjaszewski, J. Qiu, N. V. Tsarevsky and B. Charleux, J. Polym. Sci., Part A: Polym. Chem., 2000, 38, 4724-4734.

22 M. F. Cunningham, M. Xie, K. B. McAuley, B. Keoshkerian and M. K. Georges, Macromolecules, 2002, 35, 59-66.

23 D. Kukulj, T. P. Davis and R. G. Gilbert, Macromolecules, 1997, 30, 7661-7666.

24 M. Lansalot, C. Farcet, B. Charleux, J.-P. Vairon and R. Pirri, Macromolecules, 1999, 32, 7354-7360.
25 D. Crespy and K. Landfester, Beilstein J. Org. Chem., 2010, 6, 1132-1148.

26 K. Landfester, Angew. Chem., Int. Ed. Engl., 2009, 48, 44884507.

27 J. M. Asua, Prog. Polym. Sci., 2014, 39, 1797-1826.

$28 \mathrm{~J} . \mathrm{Hu}, \mathrm{M}$. Chen and L. Wu, Polym. Chem., 2011, 2, 760-772.

29 P. A. Lovell and M. S. El-Aasser, Emulsion polymerization and emulsion polymers, John Wiley \& Sons, 1997.

30 K. Landfester, Angew. Chem., Int. Ed., 2009, 48, 4488-4507.

31 F. J. Schork, Y. Luo, W. Smulders, J. P. Russum, A. Butté and K. Fontenot, in Polymer particles, Springer, 2005, pp. 129-255.

32 M. Khan, T. R. Guimarães, D. Zhou, G. Moad, S. Perrier and P. B. Zetterlund, J. Polym. Sci., Part A: Polym. Chem., 2019, 57, 1938-1946.

33 D. Mouran, J. Reimers and F. J. Schork, J. Polym. Sci., Part A: Polym. Chem., 1996, 34, 1073-1081.

34 C. Chern and T. Chen, Colloid Polym. Sci., 1997, 275, 546554.

35 K. Landfester, N. Bechthold, F. Tiarks and M. Antonietti, Macromolecules, 1999, 32, 2679-2683.

36 L. L. Hecht, A. Schoth, R. Muñoz-Espí, A. Javadi, K. Köhler, R. Miller, K. Landfester and H. P. Schuchmann, Macromol. Chem. Phys., 2013, 214, 812-823.

37 Y. Chong, J. Krstina, T. P. Le, G. Moad, A. Postma, E. Rizzardo and S. H. Thang, Macromolecules, 2003, 36, 2256-2272.

38 J. Chiefari, R. T. Mayadunne, C. L. Moad, G. Moad, E. Rizzardo, A. Postma, M. A. Skidmore and S. H. Thang, Macromolecules, 2003, 36, 2273-2283.

39 A. Butté, G. Storti and M. Morbidelli, Macromolecules, 2000, 33, 3485-3487.

40 J. McLeary, M. Tonge, D. De Wet Roos, R. Sanderson and B. Klumperman, J. Polym. Sci., Part A: Polym. Chem., 2004, 42, 960-974.

41 G. Qi and F. J. Schork, Langmuir, 2006, 22, 9075-9078.

42 X. Zhou, P. Ni and Z. Yu, Polymer, 2007, 48, 6262-6271.

43 L. Yang, Y. Luo and B. Li, Polymer, 2006, 47, 751-762.

44 S. W. Prescott, M. J. Ballard, E. Rizzardo and R. G. Gilbert, Macromolecules, 2002, 35, 5417-5425.

45 R. W. Simms, T. P. Davis and M. F. Cunningham, Macromol. Rapid Commun., 2005, 26, 592-596.

46 J. G. Tsavalas, F. J. Schork, H. de Brouwer and M. J. Monteiro, Macromolecules, 2001, 34, 3938-3946.

47 Y. Luo, B. Liu, Z. Wang, J. Gao and B. Li, J. Polym. Sci., Part A: Polym. Chem., 2007, 45, 2304-2315.

48 M. Tonge, J. McLeary, J. Vosloo and R. Sanderson, Macromol. Symp., 2003, 193, 289-304.

49 M. Park, K. Kim, A. K. Mohanty, H. Y. Cho, H. Lee, Y. Kang, B. Seo, W. Lee, H. B. Jeon and H. j. Paik, Macromol. Rapid Commun., 2020, 41, 2000399.

50 Z. Huang, P. Pan and Y. Bao, J. Polym. Sci., Part A: Polym. Chem., 2016, 54, 2092-2101.

51 A. V. Fuchs and K. J. Thurecht, Macromol. Chem. Phys., 2015, 216, 1271-1281.

52 C. Boyer, V. Bulmus, T. P. Davis, V. Ladmiral, J. Liu and S. Perrier, Chem. Rev., 2009, 109, 5402-5436. 
53 Y. Gnanou, L. Leibler and K. Matyjaszewski, Macromolecular Engineering: Precise Synthesis, Materials Properties, Applications, Wiley-VCH, 2007.

54 L. A. Fielding, M. J. Derry, V. Ladmiral, J. Rosselgong, A. M. Rodrigues, L. P. Ratcliffe, S. Sugihara and S. P. Armes, Chem. Sci., 2013, 4, 2081-2087.

55 C. T. Hendley IV, L. A. Fielding, E. R. Jones, A. J. Ryan, S. P. Armes and L. A. Estroff, J. Am. Chem. Soc., 2018, 140, 7936-7945.

56 A. H. Milani, L. A. Fielding, P. Greensmith, B. R. Saunders, D. J. Adlam, A. J. Freemont, J. A. Hoyland, N. W. Hodson, M. A. Elsawy and A. F. Miller, Chem. Mater., 2017, 29, 31003110 .

57 W. Cai, W. Wan, C. Hong, C. Huang and C. Pan, Soft Matter, 2010, 6, 5554-5561.

58 Z. Li, H. Tam, L. Xu and Q. Zhang, Opt. Lett., 2005, 30, 1117-1119.

59 N. Chaix, C. Gourgon, S. Landis, C. Perret, M. Fink, F. Reuther and D. Mecerreyes, Nanotechnology, 2006, 17, 4082 .

60 L. J. Guo, J. Phys. D: Appl. Phys., 2004, 37, R123.

61 R. P. Held, C. C. Roberts and P. F. McIntyre, Amphoteric dispersants and their use in inkjet inks, US Pat., US7932306B2, 2011.

62 C. González-Chomón, M. Silva, A. Concheiro and C. Alvarez-Lorenzo, Acta Biomater., 2016, 41, 302-311.

63 H. Li, J. Liu, L. Lin, Q. Mu, X. Sun and X. Liu, Polym. Sci., Ser. B, 2014, 56, 855-862.

64 E. Takiyama and J. Hasegawa, Stainproofing paint composition and method for producing same, US Pat., US5264466A, 1993.

65 A. C. Chen, D. L. Siegfried and D. S. Mueller, Stain-resistant no-mix orthodontic adhesive, US Pat., US4792577, 1988.

66 M. M. Skoultchi and D. K. Ray-Chaudhuri, Transparent two-part acrylic adhesive composition and the method of use thereof, US Pat., US5310835A, 1994.

67 K. J. Bachus, K. J. Langille, Y. Fu, G. T. Gibson and R. D. Oleschuk, Polymer, 2015, 58, 113-120.

68 J. Ou, G. T. Gibson and R. D. Oleschuk, J. Chromatogr., A, 2010, 1217, 3628-3634.

69 C. Yoon, H. S. Kwon, J. S. Yoo, H. Y. Lee, J. H. Bae and J. H. Choi, Color. Technol., 2015, 131, 2-8.

70 A. Aqel, K. Yusuf, Z. A. Al-Othman, A. Y. Badjah-HadjAhmed and A. A. Alwarthan, Analyst, 2012, 137, 43094317.

71 A. Aqel, Z. A. ALOthman, K. Yusuf, A. Y. Badjah-HadjAhmed and A. A. Alwarthan, J. Chromatogr. Sci., 2014, 52, 201-210.

72 A. Kharel, C. Hall, P. Černoch, P. Stepanek and T. P. Lodge, Macromolecules, 2020, 53, 885-894.

73 K. Hashimoto, Y. Kobayashi, H. Kokubo, T. Ueki, K. Ohara, K. Fujii and M. Watanabe, J. Phys. Chem. B, 2019, 123, 4098-4107.

74 T. Ueki, Polym. J., 2014, 46, 646-655.
75 S.-P. Wen, J. G. Saunders and L. A. Fielding, Polym. Chem., 2020, 11, 3416-3426.

76 M. Kocik, O. Mykhaylyk and S. Armes, Soft Matter, 2014, 10, 3984-3992.

77 L. A. Fielding, J. A. Lane, M. J. Derry, O. O. Mykhaylyk and S. P. Armes, J. Am. Chem. Soc., 2014, 136, 5790-5798.

78 I. Benito, M. Garcia, C. Monge, J. Saz and M. Marina, Colloids Surf., A, 1997, 125, 221-224.

79 S. Nilsson, Macromolecules, 1995, 28, 7837-7844.

80 L. Zhang, X. Zhang, P. Zhang, Z. Zhang, S. Liu and B. Han, Colloids Surf., A, 2018, 553, 225-229.

81 Z. Ujhelyi, F. Fenyvesi, J. Varadi, P. Feher, T. Kiss, S. Veszelka, M. Deli, M. Vecsernyes and I. Bacskay, Eur. J. Pharm. Sci., 2012, 47, 564-573.

82 L. L. Hecht, C. Wagner, K. Landfester and H. P. Schuchmann, Langmuir, 2011, 27, 2279-2285.

83 K. Landfester, N. Bechthold, S. Förster and M. Antonietti, Macromol. Rapid Commun., 1999, 20, 81-84.

84 K. Landfester, N. Bechthold, F. Tiarks and M. Antonietti, Macromolecules, 1999, 32, 5222-5228.

85 A. J. van Zyl, D. de Wet-Roos, R. D. Sanderson and B. Klumperman, Eur. Polym. J., 2004, 40, 2717-2725.

86 H. Huang, H. Zhang, J. Li, S. Cheng, F. Hu and B. Tan, J. Appl. Polym. Sci., 1998, 68, 2029-2039.

87 R. J. Young and P. A. Lovell, Introduction to polymers, CRC press, 2011.

88 G. Moad, E. Rizzardo and S. H. Thang, Aust. J. Chem., 2005, 58, 379-410.

89 A. Goto, K. Sato, Y. Tsujii, T. Fukuda, G. Moad, E. Rizzardo and S. H. Thang, Macromolecules, 2001, 34, 402-408.

90 S. Garnier and A. Laschewsky, Macromolecules, 2005, 38, 7580-7592.

91 D. B. Thomas, A. J. Convertine, L. J. Myrick, C. W. Scales, A. E. Smith, A. B. Lowe, Y. A. Vasilieva, N. Ayres and C. L. McCormick, Macromolecules, 2004, 37, 8941-8950.

92 E. Rizzardo, J. Chiefari, R. T. Mayadunne, G. Moad and S. H. Thang, Synthesis of Defined Polymers by Reversible Addition-Fragmentation Chain Transfer: The RAFT Process, Controlled/Living Radical Polymerization, ACS Symposium Series, 2000, ch. 20, vol. 768, pp. 278-296, ISBN13: 9780841237070 , eISBN: 9780841218215.

93 C. Barner-Kowollik, J. F. Quinn, T. U. Nguyen, J. P. Heuts and T. P. Davis, Macromolecules, 2001, 34, 7849-7857.

94 M. C. Davies, J. V. Dawkins and D. J. Hourston, Polymer, 2005, 46, 1739-1753.

95 P. B. Zetterlund and D. R. D'hooge, Macromolecules, 2019, 52, 7963-7976.

96 H. Tobita, Macromol. Theory Simul., 2009, 18, 108-119.

97 Y. Luo, R. Wang, L. Yang, B. Yu, B. Li and S. Zhu, Macromolecules, 2006, 39, 1328-1337.

98 V. Cunningham, S. Armes and O. Musa, Polym. Chem., 2016, 7, 1882-1891.

99 Y. Ning, L. Fielding, T. Andrews, D. Growney and S. Armes, Nanoscale, 2015, 7, 6691-6702. 